\title{
Implementasi Jaringan Syaraf Tiruan Backpropagation untuk Deteksi Penyakit Tuberculosis (TB) Paru dari Citra Rontgen
}

\author{
Ledyva Depinta*, Zulfi Abdullah \\ Jurusan Fisika, Universitas Andalas \\ *ledyvadepinta@gmail.com
}

\begin{abstract}
ABSTRAK
Telah dilakukan implementasi Jaringan Syaraf Tiruan (JST) Backpropagation untuk deteksi penyakit tuberculosis (TB) paru dari citra rontgen. Input yang digunakan untuk pelatihan JST adalah citra foto rontgen paru-paru yang terdiri dari TB paru dan paru-paru normal. Proses ini diawali dengan pengolahan citra yaitu cropping, resizing, median filtering, BW Labelling dan ekstraksi fitur menggunakan wavelet haar untuk melakukan pengenalan pola penyakit TB paru. Ekstraksi fitur citra foto rontgen menggunakan fitur energi dan koefisien setiap subband yang kemudian dimasukkan ke jaringan syaraf tiruan. Pengenalan pola yang dapat dilakukan oleh JST pada penelitian ini adalah pola sebaran warna hitam dan putih dari citra rontgen yang telah melewati proses wavelet haar. Parameter yang digunakan yaitu dengan 3 hidden layer, 1 output, learning rate 0,7 dan target error 1000. Hasil pengujian JST backpropagation untuk deteksi penyakit TB paru diperoleh akurasi $79,41 \%$ dalam mendeteksi keabnormalan dari citra foto rontgen paru.

Kata kunci : Jaringan syaraf tiruan backpropagation, foto rontgen, TB paru
\end{abstract}

\section{ABSTRACT}

The implementation of backpropagation Artificial Neural Network (ANN) has been done to detect tuberculosis from $x$-ray image. Input used for ANN training are the normal and TB infected lungs $x$-ray images. This process begins with cropping, resizing, median filtering, $B W$ labelling, and feature extraction using wavelet haar. Energy feature and coefficient of each subband from x-ray images are then inputted into ANN. Pattern recognition can be performed by JST in this research is the distribution pattern of the black and white image from the x-rays that have passed through the haar wavelet.The parameters used are 3 hidden layers, 1 output, learning rate 0,7 and target of error of 1000. The testing result of artificial neural network for TB deseases detection is obtained with accuration is about 79,41\% in detecting abnormalities of lungs $x$-ray image.

Keywords : Backpropagation artificial neural network, $x$-ray, tuberculosis lungs.

\section{PENDAHULUAN}

Penyakit Tuberculosis (TB) merupakan suatu penyakit infeksi kronis atau menahun dan menular langsung yang disebabkan oleh bakteri mycobacterium tuberculosis. Biasanya penyakit ini menyerang paru-paru tanpa memandang usia dan jenis kelamin (Purnamasari, 2013). Diagnosa penyakit tuberculosis dapat dilakukan dengan menggunakan citra sinar-x (foto rontgen), CT scan dan MRI (Magnetic Resonance Imaging). Pemeriksaan menggunakan foto rontgen merupakan teknik yang paling sering digunakan, karena biayanya relatif terjangkau oleh kalangan masyarakat dan dapat memberikan hasil pemeriksaan yang berbeda secara langsung antara paru-paru sehat dan tidak sehat (Rahmadewi dan Kurnia, 2016).

Pemeriksaan TB paru dari citra hasil foto rontgen masih memiliki kekurangan. Hal ini dikarenakan pembacaan citra sinar-x oleh dokter spesialis paru masih mengandalkan pengamatan visual dalam pembacaan hasil foto rontgen sehingga penilaiannya sangat subjektif dan tidak mempunyai nilai standar yang baku. Cara dokter mengetahui penyakit TB paru yaitu dengan membandingkan citra paru-paru dari hasil citra foto rontgen dengan citra paru-paru normal. Untuk itu diperlukan perangkat lunak yang mampu mendeteksi TB paru sebagai pembanding dari kerja praktisi medis, sehingga perangkat lunak ini dapat membantu keakuratan penentuan deteksi TB paru (Wulan, 2012).

JST dapat digunakan untuk menyelesaikan masalah yang rumit atau suatu masalah dengan rumusan matematis yang tidak diketahui seperti dalam mendeteksi suatu penyakit dari citra rontgen. Ada beberapa metode pembelajaran jaringan syaraf tiruan yaitu metode backpropagation, metode percepton, metode hebb rule, metode delta rule dan lain sebagainya. Dalam penelitian ini metode jaringan syaraf tiruan yang digunakan yaitu backpropagation 
karena metode ini dapat digunakan dalam berbagai bidang untuk melakukan pengenalan pola (pattern recognition) (Puspitanigrum, 2006).

Penggunaan JST backpropagation untuk mendeteksi suatu penyakit dari citra rontgen sebelumnya telah dilakukan oleh beberapa peneliti. Wulan (2012) mendeteksi penyakit kanker paru-paru menggunakan jaringan syaraf tiruan backpropagation menggunakan variasi jumlah hidden layer yaitu 2, 4, 6, 8,10,12 yang bertujuan untuk menentukan pada variasi hidden layer berapa hasil pendeteksiannya akan bagus. Pada penelitian ini diperoleh hasil yang baik untuk 10 hidden layer dengan tingkat akurasi sebesar 86,67\% dari data uji. Purnamasari (2013), melakukan pengujian sistem deteksi penyakit TBC dengan menggunakan input dari beberapa gejala umum penyakit TBC dengan variasi learning rate dan jumlah variasi hidden layer. Dari hasilnya, JST yang telah dilatih mengenali $100 \%$ dari data.

Pada penelitian ini dilakukan pendeteksian penyakit TB paru dari citra hasil foto rontgen menggunakan jaringan syaraf tiruan backpropagation dengan tidak menggunakan variasi hidden layer dan variasi learning rate.

\section{METODE}

Data yang digunakan dalam penelitian ini adalah data hasil foto rontgen TB paru diambil dari RSUD Dr. Achmad Mochtar Bukittinggi berupa softcopy dari citra digital. Data sebanyak 64 buah terdiri dari 50 data pasien TB paru dan 14 data pasien paru normal. Dari 64 data pasien dibagi menjadi dua bagian untuk data latih dan data uji, 30 data yang meliputi 20 data TB paru dan 10 data paru normal digunakan sebagai data latih, dan 34 data yang meliputi 30 data TB paru dan 4 data paru normal digunakan sebagai data uji.

\subsection{Pengolahan Citra Hasil Foto Rontgen}

Pada hasil rekaman foto rontgen dilakukan proses pengolahan citra yang bertujuan untuk mendapatkan fitur citra menggunakan tranformasi wavelet sehingga dapat dijadikan data latih untuk jaringan syaraf tiruan. Langkah pertama yang dilakukan dalam pengolahan citra hasil foto rontgen yaitu melakukan cropping dan resizing yang bertujuan untuk memotong citra pada daerah paru dan merubah ukuran citra untuk menyamakan dimensi pikselnya. Proses cropping ini dilakukan dengan manual menggunakan photoshop dari ukuran dimensi yang berbeda-beda menjadi ukuran 3000x3000 piksel. Proses resizing dilakukan pada citra hasil cropping yaitu dengan mengubah citra menjadi berukuran 1500x1500 piksel.

Langkah kedua adalah perbaikan kualitas citra untuk memperkecil jumlah masukan dalam JST. Proses ini dilakukan melalui tresholding untuk mengubah citra menjadi citra biner dengan menginput gambar citra, setelah itu median filter untuk mengurangi noise-noise dari hasil thresholding, dilanjutkan dengan $B W$ Labelling untuk memberikan label objek-objek pada citra yang memiliki nilai intensitas hampir sama atau mirip, dan proses terakhir transformasi wavelet untuk proses ekstraksi ciri citra. Pada penelitian ini digunakan transformasi wavelet haar untuk mempresentasikan ciri tekstur dan bentuk dari suatu citra. Transformasi ini dipilih karena diperlukan waktu komputasi yang lebih kecil dibandingkan transformasi wavelet lainnya.

\subsection{Implementasi Model Jaringan Syaraf Tiruan Backpropagation pada pendeteksian Pola TB paru dari hasil foto rontgen}

Langkah-langkah penentuan jaringan syaraf tiruan backpropagation adalah sebagai berikut :

\subsubsection{Persiapan data}

Jaringan syaraf tiruan digunakan untuk proses pengklasifikasian data yang diperoleh dari pengolahan citra sebelumnya. Pertama kali yang dibutuhkan adalah data input pelatihan (training data set) atau pola yang nantinya akan dilatih ke jaringan syaraf tiruan backpropagation. Variabel atau input yang digunakan adalah hasil fitur citra yang didapatkan dari wavelet haar dengan ukuran 1x66 piksel. 


\subsubsection{Penentuan Matriks Input $\mathrm{P}$, Matriks Target Output $\mathrm{T}$ dan Data Uji}

Dari 64 data hasil foto rontgen, 30 data yang terdiri dati 20 data TB paru dan 10 data paru normal dijadikan sebagai matriks input $\mathrm{P}$ untuk pelatihan JST. Nilai 1 dan 0 dijadikan matriks sebagai target output selama proses pelatihan JST yang berarti nilai 1 dipilih untuk positif TB paru dan nilai 0 untuk negatif TB paru (paru-paru normal). 34 sisa hasil foto rontgen yang terdiri dari 30 data TB paru dan 4 data paru normal dijadikan sebagai data uji.

\subsubsection{Penentuan Struktur Jaringan dan Algoritma Pembelajaran}

Struktur JST yang digunakan pada penelitian ini adalah multilayer neural network (jaringan syaraf tiruan banyak lapisan) dengan 1 lapisan input, 3 lapisan tersembunyi dan 1 lapisan output. Jumlah neuron pada tiap lapisan tersembunyi yang dipilih pada penelitian ini adalah JST dengan konfigurasi neuron 75-25-1, artinya terdapat 75 neuron pada lapisan tersembuyi pertama, 25 neuron pada lapisan tersembunyi kedua, 1 neuron pada lapisan tersembunyi ketiga.

\subsubsection{Inisialisasi Parameter Jaringan}

Parameter jaringan yang digunakan pada penelitian ini adalah Mean Square Error (MSE) atau target error dengan nilai $1 \times 10^{-6}$, jumlah iterasi (epochs) sebanyak 1000, dan learning rate sebesar 0,7 .

\subsubsection{Pelatihan Jaringan/Perbaikan Bobot}

Sebelum data input dilatihkan ke JST, perlu dilakukan proses preprocessing atau normalisasi data, sehingga data diproses dengan nilai yang lebih kecil tanpa kehilangan karakteristik data. Normalisasi data input dan target output memungkinkan pelatihan JST menjadi lebih efisien. Pada penelitian ini preprocessing data dilakukan dengan mengubah rentang nilai data input menjadi rentang nilai yang lebih kecil yaitu [-1,1].

\subsubsection{Didapatkan hasil Bobot W dan Bias B}

Bobot $\mathrm{W}$ dan bias $\mathrm{B}$ tiap lapisan diperoleh dengan nilai acak yang akan diperbaiki selama proses pelatihan bertujuan untuk mengenal pola input ke JST.

\subsubsection{Prediksi output data untuk mendeteksi TB paru dengan JST}

Setelah program di-running, proses deteksi TB paru akan menghasilkan keluaran anew. Jika nilai anew kecil dari 0,5 hasil deteksi bernilai 0 yang berarti negatif TB (paru-paru normal), dan jika nilai anew besar dari 0,5 hasil deteksi bernilai 1 yang berarti positif TB.

\subsection{Penentuan Nilai Akurasi}

Setelah hasil deteksi didapatkan dari program deteksi jaringan syaraf tiruan backpropagation. Dilakukan pengujian data untuk menentukan tingkat akurasi sebagai tolak ukur keberhasilan dari perangkat lunak yang dibuat.

Tingkat akurasi didapatkan dari persamaan :

$$
\text { akurasi }=\frac{\text { keseluruhan jumlah data-jumlah data salah }}{\text { keseluruhan jumlah data }} \times 100 \%
$$

\section{HASIL DAN DISKUSI}

\subsection{Perbaikan Kualitas Citra}

Perbaikan kualitas citra atau biasa disebut teknik preprocessing merupakan tahapan awal pengolahan suatu citra. Berikut penjelasan dari hasil perbaikan kualitas citra :

\subsubsection{Tresholding}

Proses thresholding berfungsi untuk menghilangkan background dari citra asli sehingga hasil dari tresholding pada citra foto rontgen menjadi warna hitam dan putih, dapat dilihat pada Gambar 1. 


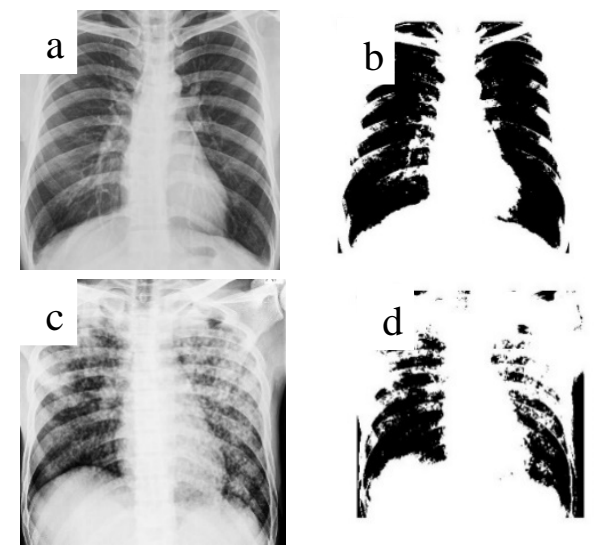

Gambar 1 Hasil proses tresholding (a) Citra paru normal sebelum tresholding, (b) Citra paru normal setelah tresholding, (c) Citra TB paru sebelum tresholding, (d) Citra TB paru setelah tresholding

\subsubsection{Filter Median}

Filter median untuk menghilangkan noise-noise kecil dari hasil tresholding. Noise yang dimaksud pada proses ini adalah menghilangkan bintik-bintik warna hitam yang terdapat pada citra foto rontgen dari hasil tresholding. Pada Gambar 2 dapat dilihat citra hasil filter median memiliki tekstur yang lebih halus dibandingkan sebelum dilakukan proses filtering.

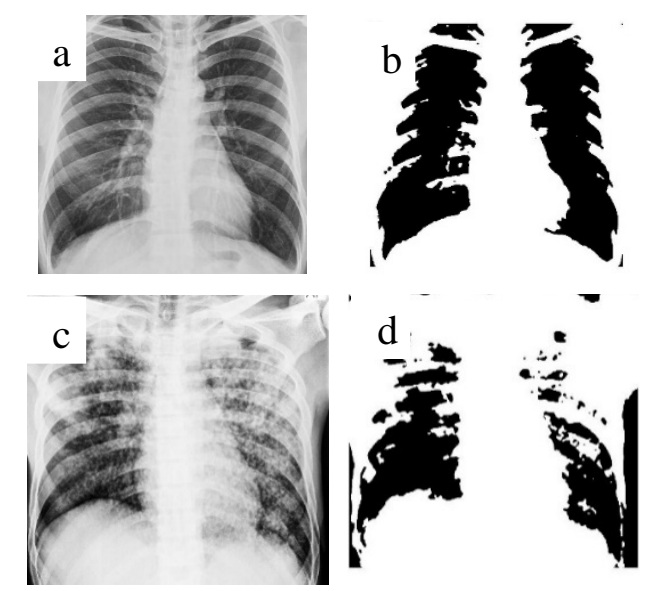

Gambar 2 Hasil proses filter median (a) Citra paru normal sebelum filter median, (b) Citra paru normal setelah filter median, (c) Citra TB paru sebelum filter median, (d) Citra TB paru setelah filter median

\subsubsection{BW Labelling}

Proses ini berfungsi untuk menandai objek-objek yang ada pada citra yang memiliki intensitas hampir sama atau mirip. Hasil proses $B W$ Labelling dari citra hasil foto rontgen tidak berbeda dari hasil filter median. Hal ini karena objek-objek pada citra seperti jaringan lain dan TB paru memiliki nilai intensitas yang hampir sama sehingga dinggap sebagai satu objek, sedangkan objek lain seperti paru-paru memiliki nilai intensitas yang sangat berbeda sehingga dianggap sebagai objek yang berbeda. Pada Gambar 3 dapat dilihat hasil BW labelling. 


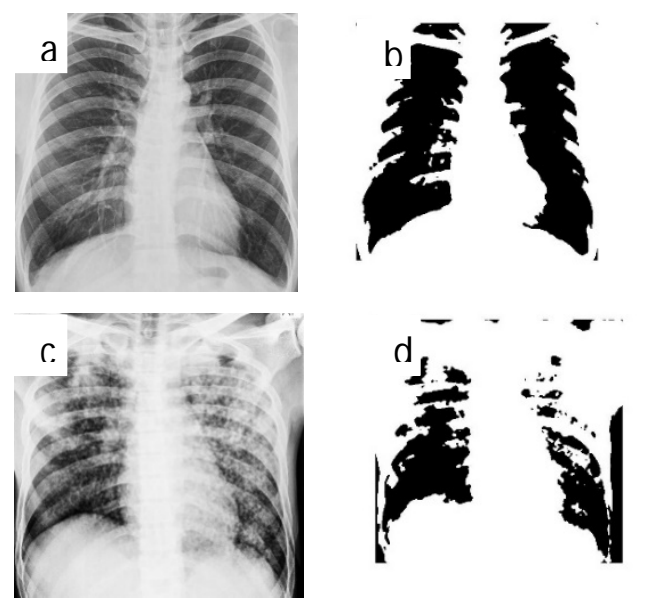

Gambar 3 Hasil proses BW Labelling (a) Citra paru normal sebelum BW Labeling, (b) Citra paru normal setelah BW Labeling, (c) Citra TB paru sebelum BW Labeling, (d) Citra TB paru setelah BW Labeling

\subsection{Implementasi Jaringan Syaraf Tiruan Backpropagation}

JST backpropagation dibangun dan dilatihkan dengan neural network toolbox. Pada saat pendeklarasian jaringan, Matlab secara otomatis akan menginialisasi bobot-bobot dan bias tiap lapisan dengan nilai random, nilai bobot dan bias inilah yang akan diperbaiki selama proses pelatihan.

Pelatihan bertujuan untuk mengenalkan pola input ke JST. JST dianggap telah mampu mengenali pola yang dilatihkan jika telah mencapai nilai MSE yang diinginkan. Gambar 4 di bawah ini menunjukkan grafik hasil pelatihan JST yang menunjukkan perubahan nilai MSE selama proses pelatihan dengan 3 hidden layer. Pada grafik dapat dilihat nilai MSE yang dihasilkan setiap iterasi (epochs) selama pelatihan sampai diperoleh nilai MSE yang diinginkan $\left(\mathrm{MSE}=1 \times 10^{-6}\right)$.

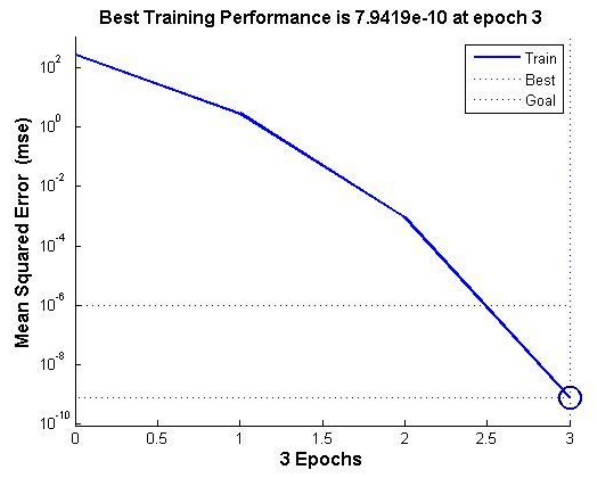

Gambar 4 Grafik Pelatihan JST dengan MSE 1x10-6 menggunakan 3 hidden layer

Selama proses pelatihan, bobot-bobot dan bias akan diubah secara terus menerus. Hal ini bertujuan agar JST dapat menyesuaikan bobot-bobot setiap lapisan sengan target output. Bobot ini akan berubah sampai mencapai nilai MSE $1 \times 10^{-6}$.

\subsection{Pengujian Data}

Pengujian data dari 34 data uji pada perangkat lunak yang terdiri dari 30 data TB paru dan 4 data paru normal, dengan target nilai 1 untuk TB paru dan 0 untuk non TB. Berdasarkan 34 data uji terdapat 7 data yang tidak sesuai dengan hasilnya, yang terdiri dari 5 buah data TB mendapatkan nilai 0 yang berarti terdeteksi kedalam kategori paru normal, dan 2 buah data paru normal mendapatkan nilai 1 yang berarti terdeteksi TB paru. Hal ini terjadi karena data yang digunakan dalam proses pelatihan jaringan syaraf tiruan backpropagation terlalu sedikit, sehingga hasil deteksi citra foto rontgen tidak sesuai dengan data ujinya. Dari sini dapat dilihat 
hasil tingkat akurasi berdasarkan jumlah data uji yang digunakan dalam proses pelatihan yaitu $79,41 \%$. Tabel 1 adalah hasil simulasi input dari data latih berdasarkan data uji.

Tabel 1 Hasil Simulasi Input Data Pelatuhan

\begin{tabular}{cccccccc}
\hline No. & $\begin{array}{c}\text { Target } \\
\text { Output } \\
(\mathbf{T})\end{array}$ & $\begin{array}{c}\text { Hasil } \\
\text { Simulasi } \\
(\mathbf{a})\end{array}$ & Kesimpulan & No. & $\begin{array}{c}\text { Target } \\
\text { Output } \\
(\mathbf{T})\end{array}$ & $\begin{array}{c}\text { Hasil } \\
\text { Simulasi } \\
(\mathbf{a})\end{array}$ & Kesimpulan \\
\hline 1. & 1 & 0 & Salah & 18. & 1 & 1 & Benar \\
2. & 1 & 1 & Benar & 19. & 1 & 1 & Benar \\
3. & 1 & 1 & Benar & 20. & 1 & 1 & Benar \\
4. & 1 & 1 & Benar & 21. & 0 & 0 & Benar \\
5. & 1 & 1 & Benar & 22. & 1 & 1 & Benar \\
6. & 1 & 1 & Benar & 23. & 1 & 1 & Benar \\
7. & 0 & 0 & Benar & 24. & 1 & 1 & Benar \\
8. & 1 & 1 & Benar & 25. & 1 & 1 & Benar \\
9. & 1 & 1 & Benar & 26. & 1 & 1 & Benar \\
10. & 1 & 1 & Benar & 27. & 1 & 1 & Benar \\
11. & 1 & 0 & Salah & 28. & 0 & 1 & Salah \\
12. & 1 & 1 & Benar & 29. & 1 & 0 & Salah \\
13. & 1 & 1 & Benar & 30. & 1 & 1 & Benar \\
14. & 0 & 1 & Salah & 31. & 1 & 1 & Benar \\
15. & 1 & 1 & Benar & 32. & 1 & 1 & Benar \\
16 & 1 & 1 & Benar & 33. & 1 & 0 & Salah \\
17. & 1 & 1 & Benar & 34. & 1 & 0 & Salah \\
\hline
\end{tabular}

\section{KESIMPULAN}

Berdasarkan kinerja jaringan syaraf tiruan backpropagation dengan 3 hidden layer, 1 output, learning rate 0,7 dan target error 1000 dalam mendeteksi penyakit TB paru dari citra hasil foto rontgen diperoleh tingkat akurasi hingga 79,41\% menggunakan 34 data uji dan 30 data data latih yang dimasukkan pada perangkat lunak jaringan syaraf tiruan backpropagation.

\section{DAFTAR PUSTAKA}

Purnamasari, R. W., 2013, Implementasi jaringan Syaraf Tiruan Backpropagation Sebagai Sistem Deteksi Penyakit TBC, Skripsi, Jurusan Matematika UNNES Semarang

Rahmadewi, R., dan Kurnia, R., 2016, Klasifikasi Penyakit Paru Berdasarkan Citra Rontgen dengan Metoda Segmentasi Sobel, Jurnal Nasional Teknik Elektro, Volume 5, Nomor 1, Jurusan Teknik Elektro Unand.

Wulan, T. D., 2012, Deteksi Kanker Paru-Paru Dari Citra Foto Rontgen Menggunakan Jaringan Saraf Tiruan Backpropagation, Skripsi, Fakultas Sains dan Teknologi, Universitas Airlangga, Surabaya

Puspitaningrum, D., 2006. Pengantar Jaringan Syaraf Tiruan. Yogyakarta: ANDI. 